\title{
Ouverture de 'Public Governance and Global Markets'
}

\author{
Silvio M. Brondoni*
}

\begin{abstract}
Traditional European governance models, created essentially to safeguard the prerogatives of nation-states, are unable to counter global networks because they are limited, on the one hand, to forming supranational institutions (to offset the influence of global networks) and, on the other, to decentralizing administrative power at the local level (to re-affirm their legitimacy in the system).

Moreover, numerous exogenous factors (not effectively controllable at the local level and exceeding European boundaries because an expression of a wider globalisation process) compel individual nation-states to adopt a global, more integrated vision and a common Public Governance system.
\end{abstract}

Keywords: Public Governance; Globalisation; European Public Governance; Nation-States; Socio-Economic Complexity

\section{Overture}

Globalisation generates new social and economic complexities that induce nation-states - under conditions of increasingly open and more permeable communication - to compare their different growth potentials and thus to adopt different policies based on their specific cultural, socio-economic, educational, and welfare aspects. Moreover, globalisation underscores the importance of creating a supranational Public Governance system to govern relations among the public bodies of different nations, the principal aim being to abandon a strictly local institutional scenario characterised by excessive bureaucracy and an overabundance of checks and formal authorisations: in short, a model whose hierarchy emphasises and enforces the power of local authorities.

Overcoming this traditional governance model calls attention to the importance of the inter-institutional relations of each public body within strategies and policies that tackle shared problems by integrating and exchanging knowledge among public institutions.

\footnotetext{
* Editor-in Chief Symphonya. Emerging Issues in Management (silvio.brondoni@ unimib.it)
} 


\section{For European Public Governance: Nation-States and Socio-Economic Complexity}

The European Commission's White Paper on Governance (Brussels, 2001), an important contribution to the development of European Public Governance at the supranational level, expounded five principles applicable to all levels of government (global, European, national, regional, and local). The first is Openness, i.e., that institutions should work in a more open manner, using language that is accessible and understandable for the general public, in order to increase public trust in complex institutions. Likewise, the White Paper stresses the importance of Participation, stating that the quality, relevance, and effectiveness of EU policies depend on ensuring wide participation by the people and their trust in the institutions dictating the policies.

Great importance is given to Accountability: each EU Institution must clearly explain and take responsibility for its role in Europe. On the other hand, policies must be effective and timely, delivering what is needed on the basis of clear and measurable objectives (Effectiveness).

The fifth principle is Coherence. The Commission emphasises that policies and actions must be coherent and easily understood because the range of tasks has grown; enlargement will increase the social and economic diversity, and regional and local authorities are increasingly involved in EU policies and decisions.

In brief, the European Commission's White Paper on Governance proposes principles referring to European governance, but these principles focus on solving internal problems and are therefore unsuitable for defining the EU's position with regard to the development of global public governance.

Instead, European Public Governance guidelines must now be developed by considering the above-mentioned Principles in a global context. The global scene is evolving very rapidly, and the global development models used by public institutions must therefore be re-examined, given that (with regard to aspects that interact with the economy) Public Governance will have to attempt to satisfy needs arising across the breadth of society and from the business world.

Consequently, even though based on such Principles, European governance must cross the boundaries of nation-states so as not to be limited by new supranational institutions proposing a form of European administrative decentralisation that in fact aims to reinforce local goals and programmes. For decades, European governance policies have been limited to building complex systems to defend national interests, setting up countless restrictions, rules, and conditions (especially with regard to the expansion of business on a European scale), creating progressively heavier burdens and obstacles, and failing in their primary aim of supporting more extensive and solid private and public interests. 


\section{Public Governance and Globalisation}

For Europe, the globalisation challenge now consists of becoming a highly competitive knowledge economy, capable of sustainable economic growth, accompanied by rising employment and strong social cohesion. To achieve this, European communities must take the lead in creating a new governance system, one that uses a worldwide approach for multilateral interaction with other globalstates (such as the USA, China, India, oil-exporting nations, etc.) and especially with new global business networks. In fact, networks that compete on a global scale (enhancing and exploiting intangible assets such as corporate culture, IT system, and brand equity) have such extensive and sophisticated market knowledge and data that they often compete with governments in setting short-term and longterm local development guidelines.

Traditional European governance models, created essentially to safeguard the prerogatives of nation-states, are unable to counter global networks because they are limited, on the one hand, to forming supranational institutions (to offset the influence of global networks) and, on the other, to decentralizing administrative power at the local level (to re-affirm their legitimacy in the system). As a result, nation-state guidelines and control policies are increasingly overwhelmed (and often thwarted) by global flows of capital, products, services, technology, and communication, which reduces the power of nation-states to define competition space and time even if they maintain significant influence in managing the complex balance between global business networks and local needs. Moreover, numerous exogenous factors (not effectively controllable at the local level and exceeding European boundaries because an expression of a wider globalisation process) compel individual nation-states to adopt a global, more integrated vision and a common Public Governance system. These factors include:

- the need to harmonize the control of economic policies with the systems of nation-states belonging to a defined global market (USA, China, India, oilexporting nations, etc.). Individual nation-states continue to lose control of their economic policies, due mainly to problems in maintaining a stable local base for industrial production, the national basis for corporate income tax systems, and the national basis for stimulating productive localization;

- the growing importance of global financial markets, with dependence of nation-state economies and finances on global financial brokers, on flows of foreign capital, and on rating policies that generate unstable conditions for nation-states at the international level;

- the change in welfare policies adopted by European nations in the last fifty years. Multinationals have moved production to countries that have low labour costs, more lenient safety rules, and limited environmental protection regulations. As a consequence, welfare has to adapt (with system logic) to new models of productivity, social investment, and economic development, aiming to blend the options of a country and the global context; 
- the spread of supranational media and communication channels, with characteristics that often elude control by individual nations and with technologies that make it difficult or impossible to regulate their content;

- the numerosity and independence of local and regional media which, by promoting the flow of local information, create new, active, and critical parties to the dialogue;

- the impact of globalisation of organised crime (a criminal business ranging from drug and arms traffic to the sale of technologies, organs and people), which fuels and spreads a phantom economy, devastating for the socioeconomic development and viability of nation-states. 